\title{
EFEKTIFITAS MEDIA PROMOSI KESEHATAN ASI PERAH TERHADAP PENINGKATAN PENGETAHUAN IBU BEKERJA UNTUK MEMBERIKAN ASI EKSKLUSIF
}

\author{
Luvi Dian Afriyani ${ }^{1)}$, Eti Salafas ${ }^{2)}$ \\ ${ }^{1}$ luviqanaiz@gmail.com, ${ }^{2}$ etisalafas.unw@gmail.com \\ ${ }^{1,2)}$ Prodi D3 Kebidanan Fakultas Ilmu Kesehatan Unversitas Ngudi Waluyo \\ J1. Diponegoro No 186 Kabupaten Semarang
}

\begin{abstract}
Abstrack
Exclusive breast milk can improve the quality of life for babies. The exclusive breast milk for working mother coverage in Indonesia is still low. They prefer to provide formula milk. They do'nt know that exclusive breast milk can be given with dairy breast milk. The health promotion on dairy breast milk have been carried out using various media such as leaflets but there are still unclear and less attractive. Video are expected to be more interesting and easy to understand. The purpose of this research to analyzes the effectiveness of health promotion media on dairy breast milk. The specific objectives in this research were: (1) To analyze the working mother's knowledge of dairy breast milk before and after being given health promotion with leaflets media and videos, (2) To analyze the effectiveness of leaflets media and videos on improving the knowledge of working mothers. The method is quasi-experimental (quasi-experimental), with a pre-post design approach. The analysis test used $T$ test. The results of this research were differences in knowledge before and after treatment in leaflet groups $(p=0.002)$, there are differences in knowledge before and after treatment in the video group $(p=0.0001)$. Video is more effective in health promotion $(p=0.024)$.
\end{abstract}

Key Words: Health Promotion Media, Dairy Breast Milk, Knowledge, Working Mother

\section{Abstrak}

ASI Eksklusif dapat meningkatkan kualitas hidup bayi. Cakupan ASI Eksklusif pada ibu bekerja di Indonesia masih rendah, ibu bekerja lebih memilih memberikan susu formula. Mereka kurang mengetahui ASI eksklusif dapat diberikan ketika bekerja dengan ASI perah. Promosi kesehatan ASI perah sudah dilakukan dengan menggunakan berbagai media seperti leaflet tetapi masih kurang jelas dan kurang menarik. Media video diharapkan lebih menarik dan mudah dipahami.Penelitian ini mempunyai tujuan umum untuk menganalisa efektifitas media promosi kesehatan tentang ASI perah. Tujuan khusus adalah (1) melakukan analisis terhadap pengetahuan ibu bekerja tentang ASI perah sebelum dan sesudah diberikan promosi kesehatan dengan media leaflet dan video (2) menganalisis efektifitas media leaflet dan video terhadap peningkatan pengetahuan ibu bekerja.Metode yang dipakai adalah eksperimen semu dengan pendekatan preposttest design. Analisis dilakukan dengan uji beda $t$ test. Hasil penelitian menunjukkan ada perbedaan pengetahuan sebelum dan sesudah perlakuan pada kelompok leaflet ( $p=0,002)$, ada perbedaan pengetahuan sebelum dan sesudah perlakuan pada kelompok video $(p=0,0001)$. Media video lebih efektif pada upaya promosi kesehatan $(p=0,024)$.

Kata Kunci: Media Promosi Kesehatan, ASI Perah, Pengetahuan, Ibu Bekerja

\section{Pendahuluan}

ASI adalah makanan terbaik untuk bayi. Beberapa riset membuktikan ASI dapat meningkatkan kekebalan tubuh, menjaga kesehatan bayi dan meningkatkan kualitas hidup bayi.Program ASI eksklusif dicanangkan agar seluruh ibu menyusui dapat memberikan ASI.secara eksklusif (hanya ASI saja) selama 6 bulan setelah melahirkan. Target pemberian ASI eksklusif masih rendah. Target nasional pemberian ASI Eksklusif pada bayi usia 0 - 6 bulan adalah $80 \%$. Pada tahun 2014 cakupan pemberian ASI baru 
mencapai 52,3 \% belum mencapai target nasional. ${ }^{[1]}$

Persentase pemberian ASI Eksklusif di Provinsi Jawa Tengah pada tahun 2015 sebesar $61.6 \%$ meningkat dibanding tahun 2014 yaitu sejumlah 60.07\%. ${ }^{[2]}$ Cakupan ASI Eksklusif di Kabupaten Semarang tahun 2015 sebesar $44.83 \%$ mengalami peningkatan dibandingkan tahun 2014 sebesar $44.30 \%$. Puskesmas Ambarawa memiliki cakupan ASI Eksklusif terendah di kabupaten Semarang yaitu $22.5 \%$. $^{[3]}$

Rendahnya pemberian ASI Eksklusif ini dipengaruhi oleh beberapa faktor antara lain faktor sikap dan perilaku ibu, tingkat pendidikan, pengetahuan, sosial ekonomi dan budaya, ibu merasa ASI yang dimiliki kurang, ibu yang bekerja, dukungan keluarga serta lingkungan. ${ }^{[4]}$ Berdasarkan hasil penelitian dilaporkan bahwa $52 \%$ ibu bekerja mengalami kesulitan dalam memberikan ASI Eksklusif hal ini dipengaruhi oleh pekerjaan waktu penuh dan jumlah anggota keluarga. ${ }^{[5]}$ Ibu Bekerja adalah salah satu faktor yang menyebabkan ketidakberhasilan pemberian ASI eksklusif. Beberapa ibu bekerja beranggapan bahwa ibu yang bekerja akan mengalami kesulitan dalam memberikan ASI sehingga banyak ibu bekerja yang memutuskan untuk beralih ke susu formula dengan alasan kemudahan. Tiga factor yang paling berkontribusi terkait pemberian ASI eksklusif adalah kesempatan meninggalkan jam pekerjaan,waktu dengan anak yang lebih panjang dan waktu kembali bekerja. ${ }^{[6]}$

Ibu bekerja dapat memberikan ASI secara eksklusif dengan memerah ASI atau disebut sebagai ASI perah, menyimpannya dengan benar sehingga manfaat ASI tidak hilang. ASI perah ini dapat diberikan kepada bayi ketika ibu sedang bekerja, sementara ditempat kerja ibu dapat memerah ASI dan menyimpannya untuk diberikan kepada bayi saat ibu tidak bersama bayi. ${ }^{[7]}$
Perlu edukasi kepada ibu menyusui yang bekerja untuk dapat memberikan ASI perah. Promosi kesehatan tentang ASI perah diharapakan dapat memberikan pemahaman dan motivasi ibu agar dapat memberikan ASI eksklusif walaupun ibu bekerja. Promosi kesehatan tentang ASI perah dilakukan dengan berbagai macam metode dan media pendukung untuk memudahkan sasaran menerima informasi kesehatan yang diberikan. Peran media sangat besar dalam upaya promosi kesehatan.Media dapat membuat sasaran lebih tertarik dan mempermudah menyerap informasi. ${ }^{[8]}$ Berdasarkan penelitian didapatkan ada perbedaan pengetahuan sebelum dan sesudah diberikan pendidikan kesehatan dengan menggunakan media cetak dan media elektronik. ${ }^{[9]}$

Berbagai macam media yang dapat digunakan untuk promosi kesehatan, dimana setiap media memiliki keunggulan dan kelemahan masing masing masing. Manfaat alat bantu visual sangat efektif, transparan, dan dapat membantu dalam pengambilan keputusan serta mengubah perilaku beresiko. $^{[10]}$

Pemberian ASI Eksklusif adalah pemberian ASI sejak bayi dilahirkan sampai sekitar umur 6 bulan. Selama itu bayi tidak diharapkan untuk mendapatkan makan tambahan seperti pisang, biscuit,nasi,timdan sebagainya. Pemberian ASI secara benar akan mencukupi kebutuhan bayi selama 6 bulan,meskipun tanpa makanan tambahan/pendamping. Diatas 6 bulan bayi memerlukan makanan tambahan tapi menyusui bisa dilanjutkan sampai 2 tahun. ${ }^{[11]}$

ASI Eksklusif memberikan berbagai manfaat bagi ibu dan bayi. Bagi bayi ASI memberikan nutrisi dengan komposisi dalam ASI sangat ideal dengan kebutuhan pertumbuhan bayi. ASI sebagai zat kekebalan tubuh akan 
melindungi bayi dari berbagai penyakit seperti diare, batuk, pilek dan infeksi. ASI meningkatkan kecerdasan bayi karena kandungan zat gizi dalam ASI berfungsi untuk pertumbuhan otak. ASI juga meningkatkan jalinan kasih sayang, pada waktu menyusui bayi akan berada sangat dekat dengan ibunya. Semakin sering bayi berada dalam dekapan ibunya, maka bayi akan semakin merasakan kasih sayang ibunya. ${ }^{[12]}$

Cara menyimpan ASI perah adalah ASI di simpan di tempat penyimpanan ASI tetap menggunakan botol kaca pada saat melakukan pemerahan ditempat kerja, karena lemak-lemak dalam ASI tidak akan menempel di dalam botol kaca dan juga botol kaca murah dan dapat digunakan berulang kali. Botol jangan diisi terlalu penuh, karena dapat menyebabkan botol pecah saat disimpan di dalam frezzer di tempat kerja, sehingga lebih baik diisi hanya sekitar $3 / 4$ botol saja.Pastikan botol penyimpanan ASI sudah dicuci bersih dengan sabun sebelum digunakan kembali.Simpan dalam botol yang steril dan tutup yang rapat dan jangan sampai ada celah yang terbuka.Botol diberi label, jam, tanggal pemerahan, dan nama untuk membedakan ASI perah ibu dengan ASI perah ibu bekerja lainnya saat melakukan pemerahan ditempat kerja, pisahkan ASI dengan bahan makanan lain di dalam lemari pendingin ditempat kerja. ${ }^{[7]}$

Cara membawa ASI perah dari tempat kerja kerumahadalah saat akan pulang, pastikan lagi ASI sudah ditutup rapat dalam botol,masukan botol ASI ke dalam termos yang sudah diisi dengan es batu. Pastikan botol bersentuhan dengan es batu di dalam termos.Cara penyimpanan ASI perah sampai di rumah yaitu ASI perah dimasukan ke dalam lemari pendingin selama 1 jam sebelum dimasukkan ke dalam frezzer. Untuk ASI berlimpah, untuk jangka panjang sebaiknya sebagian ASI perah disimpan di dalam frezzer, dan simpan dilemari pendingin dalam jangka waktu pendek, apabila dirumah tidak memiliki lemari pendingin maka ASI dapat disimpan di dalam termos yang diberi es batu. ${ }^{[7]}$

Pemberian ASI perah dengan cara sehari sebelumnya ASI perah beku yang tersimpan di dalam frezzer diturunkan kelemari pendingin. Tujuannya agar pelelehan ASI perah beku dapat mencair selama beberapa saat.ASI perah dikeluarkan dari lemari es secara berurutan dari jam perah paling awal.Mengambil ASI perah sesuai dengan kebutuhan, yang bisa dihabiskan langsung oleh bayi. ASI perah dihangatkan terlebih dahulu dengan cara botol direndam dalam air hangat, ASI perah tidak dihangatkan dengan air mendidih atau direbus karena akan merusak kandungan gizi, Menyiapkan cangkir kecil atau cangkir dan sendok untuk meminumkan ASI perah kepada bayi.Jika ASI perah sudah mencair, ASI mesti dikocok perlahan (memutar searah jarum jam) agar cairan di atas bercampur dengan cairan bawah.Cairan atas biasanya terlihat agak kental, dikarenakan kandungan lemak yang lebih banyak. ${ }^{[7]}$

Daya tahan ASI perah juga harus diperhatikan dan perlu diajarkan kepada ibu - ibu yang bekerja. Apabila ASI disimpan pada bagian kulkas bawah dengan suhu $0-4^{0} \mathrm{C}$ untuk mencairkan ASI yang beku dapat bertahan selama 24 jam saja. Untuk ASI yang baru diperah dapat disimpan dipertengahan kulkas dengan suhu $4^{0} \mathrm{C}$ ASI dapat bertahan selama 5 hari.Untuk ASI yang disimpan di dalam freezer dengan suhu $-18^{\circ} \mathrm{C}$ dapat bertahan selama 3-6 bulan. $^{[7]}$

Alat yang digunakan oleh pendidik dalam menyampaikan bahan pendidikan/pengajaran. Media pendidikan disebut juga sebagai alat peraga karena berfungsi memperagakan sesuatu dalam proses 
pendidikan/pengajaran. ${ }^{[13]}$ Manfaat media adalah menimbulkan minat sasaran pendidikan, mencapai sasaran yang lebih banyak, membantu mengatasi banyak hambatan dalam pemahaman, menstimulasi sasaran pendidikan untuk meneruskan pesan pesan yang diterima kepada orang lain, mempermudah penyampaian bahan atau informasi kesehatan, mempermudah penerimaan informasi oleh sasaran/masyarakat, mendorong keinginan orang untuk mengetahui, kemudian mendalami dan akhirnya mendapatkan pengertian yang lebih baik serta membantu menegakkan pengertian yang diperoleh. ${ }^{[14]}$

\section{Metode Penelitian}

Penelitian ini menggunakan metode quasi experiment. Terdiri dari 3 tahap. Tahap pertama dilakukan kajian terhadap pengetahuan tentang ASI perah pada ibu bekerja. Tahap kedua memberikan perlakuan pada 2 kelompok sampel. Kelompok pertama menggunakan media leaflet dan kelompok kedua menggunakan media video.Tahap ketiga menganalisis efektifitas media leaflet dan video terhadap peningkatan pengetahuan ibu bekerja tentang ASI perah. Penelitian ini dilakukan di wilayah kerja Puskesmas Ambarawa.

Pengumpulan data menggunakan instrumen kuesioner terstruktur. Sebelum melakukan kegiatan dilakukan terlebih dahulu penyusunan dan uji coba kuesioner. Penelitian dilakukan dengan mendapatkan data primer melalui wawancara terstruktur dengan responden. Pengetahuan responden sebelum dan sesudah dilakukan perlakuan, dianalisis dengan metode descriptive analysis. Efektifitas setiap media dianalisis dengan uji $t$ test dependent, sedangkan analisis efektifitas media leaflet dan video menggunakan uji t test independent.

\section{Hasil dan Pembahasan}

Tabel 1 Perbedaan pengetahuan responden sebelum dan sesudah promosi kesehatan menggunakan media leaflet

\begin{tabular}{lcccccc}
\hline Kelompok & Penilaian & Min & Max & Mean & SD & P \\
\hline $\begin{array}{l}\text { Sebelum } \\
\text { perlakuan }\end{array}$ & Pengetahuan & 15 & 22 & 17,53 & 2,030 & \\
\cline { 1 - 5 } $\begin{array}{l}\text { Sesudah } \\
\text { perlakuan }\end{array}$ & Pengetahuan & 16 & 24 & 15 & 2,631 & \\
\hline
\end{tabular}

Hasil penelitian menunjukkan bahwa rata rata pengetahuan responden sebelum perlakuan adalah 15 dan naik menjadi 17,53 setelah dilakukan promosi kesehatan menggunakan leaflet. Peningkatan pengetahuan tersebut diartikan sebagai hasil dari promosi kesehatan melalui penyuluhan dengan media leflet. Informasi merupakan salah satu faktor yang mempengaruhi pengetahuan seseorang. ${ }^{[8]}$

Pemberian informasi dengan menggunakan media leaflet mempermudah penyampaian bahan atau informasi kesehatan dan mempermudah penerimaan informasi oleh sasaran/masyarakat. Sejalan dengan hasil penelitian Kawuriansari,Rarsa dkk (2010) tentang studi efektivitas leaflet terhadap skor pengetahuan remaja putri tentang disminore di SMP Kristen 01 Purwokerto Kebupaten Banyumas didapatkan hasil bahwa media leaflet mempunyai efektivitas terhadap skor remaja putri tentang disminor dengan nilai $\mathrm{p}=0,001$. $^{[15]}$

Media leaflet yang digunakan adalah media dua dimensi yang menampilkan kombinasi tulisan dan gambar yang lebih memudahkan responden untuk menerima informasi yang diberikan. Disarankan untuk menggunakan media yang banyak menggunakan alat alat visual karena akan mempermudah penyampaian dan penerimaan informasi oleh masyarakat. ${ }^{[14]}$ Manfaat alat bantu visual sangat efektif, transparan, dan 
dapat membantu dalam pengambilan keputusan serta mengubah perilaku beresiko. ${ }^{[10]}$ Hasil ini sejalan dengan penelitian Handayani,Sri (2010) terdapat peningkatan pengetahuan siswa remaja tentang kesehatan reproduksi remaja yang mendapat perlakuan menggunakan media leaflet. ${ }^{[16]}$

Hasil uji statistik didapatkan bahwa $\mathrm{p}=$ 0,02 , menunjukkan bahwa pada alpha 5 $\%$ didapatkan ada perbedaan pengetahuan sebelum dan sesudah diberikan promosi kesehatan dengan media leaflet. ${ }^{[17]}$ Media komunikasi sabagai alat bantu pembelajaran mutlak diperlukan oleh para tenaga kesehatan dalam kegiatan upaya promosi kesehatan. Hal ini sejalan dengan penelitian

Tabel 2 Perbedaan pengetahuan responden sebelum dan sesudah pada promosi kesehatan menggunakan media video

\begin{tabular}{lcccccc}
\hline Kelompok & Penilaian & Min & Max & Mean & SD & p \\
\hline $\begin{array}{l}\text { Sebelum } \\
\text { perlakuan }\end{array}$ & Pengetahuan & 9 & 19 & 16,00 & 3,509 & \\
\cline { 1 - 5 } $\begin{array}{l}\text { Sesudah } \\
\text { perlakuan }\end{array}$ & Pengetahuan & 15 & 25 & 20,60 & 2,354 & \\
\hline
\end{tabular}

Hasil penelitian menunjukkan bahwa rata rata pengetahuan responden sebelum adalah 16 dan naik menjadi 25 setelah dilakukan promosi kesehatan menggunakan video.Peningkatan pengetahuan tersebut diartikan sebagai hasil dari promosi kesehatan melalui penyuluhan dengan media video. Pemilihan media video dalam promosi kesehatan menawarkan kegiatan penyuluhan lebih menarik dan tidak monoton,tampilan informasi berupa tulisan,suara dan gambar memberikan media ini lebih menarik.

Hasil uji statistik didapatkan bahwa $\mathrm{p}=$ 0,0001 , menunjukkan bahwa pada alpha $5 \%$ didapatkan ada perbedaan pengetahuan sebelum dan sesudah diberikan promosi kesehatan dengan media video. Sesuai hasil penelitian Kapti Rinik E,Yustina Y,Widyatuti (2013) bahwa ada perbedaan peningkatan pengetahuan pada kelompok perlakuan dan kelompok kontrol. ${ }^{18}$ Berdasarkan penelitian Priya Rachel Johns,Malarvizhi,G. ang Glory H (2015) bahwa ada perbedaan nilai pre dan post test pada responden yaitu ibu bekerja yang diberikan penyuluhan dengan media video dengan nilai $\mathrm{p}=$ 0,0001. Video ditemukan menjadi metode yang efektif dengan peningkatan rata-ratadurasi pemberian ASI eksklusif dari 3,05 bulan hingga 4,2 bulan dan perbaikan pada pengetahuan, sikap dan pengetahuan ibu. Dari hasil tersebut video dapat direkomendasikan untuk menjadi pilihan media tentang ASI perah pada ibu bekerja agar ibu bekerja tetap berhasil memberikan ASI eksklusif. ${ }^{[19]}$

Tabel 3 Efektivitas promosi kesehatan menggunkan media lealet dan video

\begin{tabular}{lllll}
\hline Pengetahuan & \multicolumn{2}{c}{ Media } & T & P \\
\cline { 1 - 3 } & Leaflet & Video & & \\
\hline Mean & -2.533 & - & - & 0.002 \\
& & 5.400 & 3.752 & \\
\hline Std. deviasi & 2.615 & 3.481 & - & 0.001 \\
& & & 6.009 & \\
\hline
\end{tabular}

Hasil uji statistik pada kedua media tersebut menunjukkan bahwa media video lebih efektif daripada leaflet dengan nialai $p: 0,024$. Sejalan denagan penelitian Herawati N, Damrim M dan Marshal J (2016) membuktikan bahwa rata rata pengetahuan dan ketrampilan media video dan leflet memberikan perbedaan yang significant terhadap pengetahuan dan ketrampilan reponden. Rata rata pengetahuan dan ketrampilan responden lebih tinggi jika menggunakaan video dan media video memiliki pengaruh yng lebih baik terhadap pengetahuan dan ketrampilan SADARI.Video sebagai media audio 
visul memiliki efektivitas yang lebih tinggi. ${ }^{[20]}$

\section{Kesimpulan}

Terdapat peningkatan pengetahuan sesudah dilkukan perlakuan, ditunjukkan dengan ada perbedaan pengetahuan sebelum dan sesudah promosi kesehatan dengan media leaflet $(\mathrm{p}=0,002)$. Terdapat peningkatan pengetahuan sesudah dilkukan perlakuan, ditunjukkan dengan ada perbedaan pengetahuan sebelum dan sesudah promosi kesehatan dengan media video $(p=0,0001)$. Media video lebih efektif dalam peningkatan pengetahuan responden $(\mathrm{p}=0,024)$. Direkomendasikan untuk menggunakan media video sebagai media promosi kesehatan ASI perah untuk meningkatkan pemberian ASI eksklusif.

\section{Ucapan Terima Kasih}

Tim Peneliti mengucapkan terima kasih kepada Direktorat Penelitian dan Pengabdian (DP2M) DIKTI, Lembaga Penelitian dan Pengabdian kepada Masyarakat (LPPM) Universitas Ngudi Waluyo, Puskesmas Ambarawa Kabupaten Semarang.

\section{Daftar Pustaka}

[1] Kemenkes RI. Profil Kesehatan Indonesia Tahun 2014. Jakarta: Kemenkes RI; 2015

[2] Dinas Kesehatan Provinsi Jawa Tengah. Profil Kesehatan Provinsi Jawa Tengah tahun 2014.Semarang: Dinkes Provinsi Jawa tengah; 2015.

[3] Dinas Kesehatan Kabupaten Semarang. Profil Kesehatan Kabupaten Semarang tahun 2014. Semarang: DKK semarang; 2015

[4] Roesli,U. Inisiasi Menyusui Dini Plus ASIE ksklusif. Jakarta: Pustaka Bunda; 2008
[5] Danso, Janet. Examining The Practice Of Exclusive Breastfeeding Among Professional Working Mothers In Kumasi Metropolis Of Ghana. International Journal of Nursing; 2014. 1:11-24.

[6] Hailu et all. Current Level and Correlation of Exclusif Breastfeeding among Employed Mothers in Debre marko's Town Nortwest Ethiopia. Journal of Community Medicine and Health; 2013

[7] Kemenkes RI. Pusdatin Kemenkes RI. Mari Dukung Menyusui dan Bekerja. Jakarta: Kemenkes RI. 2015

[8] Mubarak, Wahid Iqbal. Promosi Kesehatan untuk kebidanan. Jakarta :Salemba Medika; 2011

[9] Yustisa PF, Aryana K, Suyasa N G. Efektivitas penggunaan Media Cetak dan Media Elektronika Dalam Promosi Kesehatan terhadap peningkatan Pengetahuan dan Perubahan Sikap Siswa SD. Jurnal Kesehatan Lingkungan; 2014. 4.29-39.

[10] Retamero, Cokely. Communicating Health Risks with Visual Aids. SAGE Journals; 2013. 22. 392-399.

[11] Maruni. Inisiasi Menyusui Dini dan Manajemen Laktasi. Jakarta. Trans Info Medika; 2012

[12] Suprijadu. Asuhan Kebidanan Nifas. Ponorogo: HMP Press; 2014

[13] Maulana, Heri DJ. Promosi Kesehatan. Jakarta: EGC; 2009

[14] Notoatmodjo,Soekidjo. Promosi Kesehatan dan Perilaku Kesehatan. Jakarta: Rineka Cipta; 2012.

[15] Kawuriansari, Raras. Fajarsari, Dyah. Mulidah, Siti. Studi efektivitas Leaflet terhadap Skor 
Pengetahuan Remaja Putri tentang Dismenorea di SMP Kristen 01Purwokerto Kabupaten Banyumas. Jurnal Bidan Prada; 2010. 1: $108-122$

[16] Handayani,Sri. Perbandingan Efektivitas Pemberian Informasi Melalui Media Cerita Bergambar Komik (Versi BKKBN) dengan Media Leaflet. Jurnal Gaster; 2010. 7: 482-490

[17] Gejir,I Nyomna dkk. Media Komunikasi dalam Penyuluhan Kesehatan. Yogyakarta: ANDI; 2017

[18] Kapti Rinik E,Yustina Y,Widyatuti Efektivitas Audiovisual sebagai media penyuluhan Kesehatan Terhadap Peningkatan Pengetahuan dan Sikap Ibu dalam Tata Laksana Balita dengan Diare di Dua Rumah Sakit Kota Malang; 2013

[19] Priya Rachel Johns, Malarvizhi,G. ang Glory H. Impact Of Video Assisted Teaching Exclusive Breast Feeding On Knowledge, Attitude And Practice Of Working Lactating Mothers. International Journal of Development Research; 2015. Vol 5.Issue, 06.4776-4780

[20] Herawati N, Damrim M dan Marshal J. Studi Perbandingan Media Promosi Kesehatan antara Leaflet dengan Video terhadap Pengetahuan tentang Kanker Payudara dan Ketrampilan Deteksi Dini Kanker Payudara ( SADARI ) pada remaja Putri di Jurusan Kebidanan Poltekkes Jambi Tahun 2016.2017.Tekno-pedagogi; 2016. vol 7(2).1-14. 